\title{
Cardiac and Other Presentation and Clinical Outcomes of COVID-19 Pandemic among Different Ethnic and Religious Populations in The City of Jerusalem
}

Elad Asher ( $\sim$ el.asher@gmail.com )

Shaare Zedek Medical Center https://orcid.org/0000-0003-3381-605X

Tal Samuel

Shaare Zedek Medical Center

Oren Yagel

Hadassah Hospital Ein Kerem: Hadassah Medical Center

Arik Wolak

Shaare Zedek Medical Center

Rivka Farkash

Shaare Zedek Medical Center

Ronen Durst

Hadassah Hospital Ein Kerem: Hadassah Medical Center

Eli Ben-Chetrit

Shaare Zedek Medical Center

Yigal Helviz

Shaare Zedek Medical Center

Ariella Tvito

Shaare Zedek Medical Center

\section{Ran Nir-Paz}

Hadassah Hospital Ein Kerem: Hadassah Medical Center

Offer Amir

Hadassah Hospital Ein Kerem: Hadassah Medical Center

Michael Glikson

Shaare Zedek Medical Center

\section{Research}

Keywords: COVID-19, Jews, Arabs, Cardiology

Posted Date: November 16th, 2021 
DOI: https://doi.org/10.21203/rs.3.rs-1027907/v1

License: (c) (1) This work is licensed under a Creative Commons Attribution 4.0 International License. Read Full License

Version of Record: A version of this preprint was published at European Heart Journal on October 1st, 2021. See the published version at https://doi.org/10.1093/eurheartj/ehab724.1147. 


\section{Abstract}

Background: The COVID-19 pandemic is an ongoing global pandemic. Jerusalem with its 919,400 inhabitants has a wide variety of populations, of which $62 \%$ are Jews (36\% ultra-orthodox; $64 \%$ nonultraorthodox) and $38 \%$ Arabs which were largely affected by the pandemic. The aim of our study was to understand the different presentations, course and clinical outcomes in these different ethnical and cultural groups in Jerusalem in the COVID-19 pandemic.

Methods: We performed a cohort study of all COVID-19 patients admitted between March 9 - July 16, 2020 to the two university medical centers in Jerusalem. Patients were divided according to their religion and ethnicity into 3 main groups: 1) Ultra-Orthodox Jews; 2) other (non-Ultra-Orthodox) Jews and 3) Arabs.

Results: Six hundred and two patients comprised the study population. Of them the 361 (60\%) were UltraOrthodox Jews; 166 (27.5\%) non-Ultra-Orthodox Jews and 75 (12.5\%) Arabs. The Arab patients were younger than the Ultra-Orthodox Jews and the non-Ultra-Orthodox Jews $(51 \pm 18$ year-old vs. $57 \pm 21$ and $59 \pm 19$, respectively, $p<0.01$ ), but suffered from significantly more co-morbidities. Moreover, hemodynamic shock, ischemic ECG changes and pathological chest x-ray were all more frequent in the Ultra-Orthodox patients as compared the other groups of patients. Being an Ultra-Orthodox was independently associated with significantly higher rate of Major Adverse Cardiovascular Events (MACE) [OR=1.96; 95\% $\mathrm{Cl}(1.03-3.71), p<0.05]$. Age was the only independent risk factor associated with increased mortality rate [OR=1.10; $95 \% \mathrm{Cl}(1.07-1.13), \mathrm{p}<0.001]$.

Conclusions: The COVID-19 first phase in Jerusalem, affected different ethnical and cultural groups differently, with the Ultra-Orthodox Jews mostly affected by admission rates, presenting symptoms clinical course and MACE (Acute coronary syndrome, shock, cerebrovascular event or venous thromboembolism). It is conceivable that vulnerable populations need special attention and health planning in time of pandemic, to prevent rapid distribution and severe morbidity.

\section{What's Already Known About This Topic?}

- Worldwide, the COVID-19 pandemic has resulted in substantial mortality arising mainly from respiratory failure.

- The response to the COVID-19 pandemic in high income countries have focused on the majority population group.

- These unique groups have been shown to experience greater challenges in adopting physical distancing measures and they face barriers in gaining access to information, testing and healthcare services relative to the majority population, particularly during emergencies.

\section{What Does This Article Add?}


- The COVID-19 in Jerusalem, affected different ethnical and cultural groups differently.

- The Ultra-Orthodox Jews were mostly affected by admission rates, presenting symptoms clinical course and MACE (Acute coronary syndrome, shock, cerebrovascular event or venous thromboembolism).

- It is conceivable that vulnerable populations need special attention and health planning in time of pandemic, to prevent rapid distribution and severe morbidity.

\section{Introduction}

The COVID-19 pandemic is an ongoing global pandemic of coronavirus disease 2019, caused by severe acute respiratory syndrome coronavirus 2 (SARS-CoV-2) (1). The outbreak was first identified in December 2019 in Wuhan, China (2). The World Health Organization declared the outbreak a public health emergency of international concern on 30 January 2020 and a pandemic on 11 March (3-4). Worldwide, the COVID-19 pandemic has resulted in substantial mortality arising mainly from respiratory failure (5). The response to the COVID-19 pandemic in high income countries have focused on the majority population group but may have failed to address the special needs of minority and special ethnic groups (6). These unique groups have been shown to experience greater challenges in adopting physical distancing measures and they face barriers in gaining access to information, testing and healthcare services relative to the majority population, particularly during emergencies. It is likely that they face additional risk from COVID-19 based on their unique characteristics and culture, together with less than optimal health status. This may generate additional health risk during this pandemic, not just for minorities themselves but for society as a whole (7-9).

Israel was also seriously affected by this pandemic. The first case in Israel was confirmed on 21 February 2020, and social distancing restrictions were announced in Israel on March 11, 2020 and lasted till the end of the first wave (10). Jerusalem is the largest, most ethnically diverse city in Israel. At the end of 2018 its population was estimated to be 919,400 people, which constituted $10 \%$ of the Israeli population. Of them $569,900(62 \%)$ were Jewish and $349,600(38 \%)$ Arabs $(11,12)$. Moreover, the Jewish population is divided into ultra-orthodox (36\%), orthodox (31\%) and non-Orthodox (33\%) Jews. The ultraorthodox and the Arab populations live in separate neighborhoods that are quite uniform in their population.

According to the demographic data of Jerusalem (12), and for the purpose of this study, we divided the patients based on their home addresses according to their religion and ethnicity into 3 main population groups: 1) Ultra-Orthodox Jews; 2) other (non-Ultra-Orthodox) Jews and 3) Arabs.

Ultra-Orthodox: The ultra-Orthodox also known as Haredi Judaism, consists of multiple groups within Orthodox Judaism characterized by adherence to halakha (Jewish law) as it was perceived in the $19^{\text {th }}$ century and traditions, as opposed to current "western" practices and habits. The Ultra-Orthodox society, composing about $11 \%$ of the population in Israel and about $22 \%$ of the entire population in Jerusalem is a socio-cultural minority (13). Those groups are characterized by large families (in 2017 , their fertility rate was 7.1 children per woman) living in densely populated apartments in specific neighborhoods, similar to 
Borough Park (USA) neighborhood which is home to one of the largest Ultra- Orthodox Jewish communities outside Israel that was also significantly affected by the COVID 19. As the average number of children in Orthodox and Ultra-Orthodox families is 6.72, Borough Park is experiencing a sharp growth in population (14). Many of them practice intensive Torah studies and prayers in large groups and have low income $(6,15-17)$. At adolescence boys attend early-morning prayer 7 days a week and Torah studies in groups until the late evening hours (18). While they spend many years in religious studies, they majority of them have little or no formal secular education. Many of them follow laws and instructions set forth by local religious leaders (Rabbis) with partial observance of state laws. Most of them do not have television nor do they use internet and social media (13).

Arabs: The Arabs society composing about $38 \%$ of the total population in Jerusalem. This society is characterized by large families with $10 \%$ of families with five or more children under age 17 as compared with $7 \%$ of Jewish households $(19,20)$. Arabs average age is younger than Jews and they have lower life expectancy as compared with the Jewish population (21). The incidence of several chronic diseases (e.g., diabetes) has increased in recent years among Arabs more than among Jews (22). Lastly, there have been significant improvements in the educational levels of Arabs, but the gaps between Arabs and Jews are still large (23).

To understand the different presentation, course and outcome in these different ethnical, religious and cultural groups, we investigated all confirmed COVID-19 patients admitted to the two main medical centers in, who took care of all COVID-19 cases admitted in Jerusalem.

\section{Methods}

We performed a cohort study of all COVID-19 patients admitted between March 9 -July 16, 2020 (first wave) to the two university medical centers in Jerusalem, Shaare Zedek and Hadassah-Hebrew University Medical Center, which were the only ones admitting COVID-19 patients, each having approximately 1000 beds. Data were anonymously documented in each unit by the local coordinator and prospectively submitted into an electronic case report form (eCRF). Data were checked for accuracy and out-of-range values by the coordinating unit.

\section{Ethical Approval and Consent to participate}

The Shaare Zedek Medical Center Institutional review board and the Hadassah medical center Institutional review board approved the study on the basis of strict maintenance of participants' anonymity by de-identifying during database analysis. Informed consent was waived by both the Shaare Zedek Medical Center and the Hadassah medical center Institutional review boards. Moreover, the authors have no conflicts of interest to declare. No Funding was applied for the study. All methods were performed in accordance with the relevant guidelines and regulations.

\section{Data collection}


We studied 683 consecutive adult patients ( $\geq 18$ years old) admitted with a diagnosis of COVID-19 infection. All patients had a diagnosis confirmed by a positive reverse transcriptase- polymerase chain reaction (PCR) from one of the fourth assay for SARS-CoV-2 in a respiratory tract sample available in Israel (Center of disease control assay; BGI, homemade base on EU protocol, Focus Diagnostics Inc., Cypress, CA; GeneXpert ${ }^{\circledR}$ and Seegene Allplex ${ }^{\text {TM }}$ 2019-nCoV Assay). Demographic data, presenting symptoms, comorbid conditions, medications and physical examination were systematically recorded. Laboratory and imaging data were collected as well. Clinical deterioration was defined as either death or respiratory, hemodynamic or cardiac deterioration. Respiratory deterioration was defined as acute new onset hypoxemia requiring mechanical ventilation, extracorporeal membrane oxygenation (ECMO), or both. Hemodynamic deterioration was defined as persistent hypotension requiring vasopressors to maintain mean arterial pressure $\geq 65 \mathrm{mmHg}$ and having serum lactate level $>2 \mathrm{mmol} / \mathrm{L}$ despite adequate volume resuscitation (25). Myocardial injury was defined as either increase in serum levels of cardiac troponin-I above the 99th percentile upper reference limit, or malignant arrhythmia (defined as rapid ventricular tachycardia lasting more than 30 seconds, inducing hemodynamic instability and/or ventricular fibrillation). Follow-up for mortality rate at 30-day was drawn from the national health registry.

\section{Statistical analysis}

Demographic, clinical features, and the use of in-hospital therapies were reported for all study participants. Continuous variables were presented as mean \pm SD or median and inter-quartile range, and categorical variables were expressed as percentages. Continuous variables were compared between groups using Kruskal-Wallis test by ranks per Mann Whitney U test. Categorical variables were compared using Chi-squared test. All tests were two-sided, and values of $p<0.05$ were considered statistically significant. Multivariable logistic regression models were conducted in order to identify independent predictors for (1) in-hospital and 30-day mortality and (2) major adverse cardiovascular event (MACE), which was defined as one or more of the following: Acute coronary syndrome (ACS), shock, cerebrovascular event (CVA) or venous thromboembolism (VTE). The models included the following prespecified covariates: 1) age (continuous); 2) any cardiac risk factor (known atherosclerosis vascular disease, dyslipidemia, hypertension, diabetes mellitus, past or present smoking, previous coronary revascularization and/or heart failure); 3) gender and 4) Ultra-Orthodox using non-Ultra-Orthodox and Arabs populations as reference group. Statistical analyses were carried out using SPSS statistical software. (IBM SPSS Statistics for Windows, Version 25.0. Armonk, NY: IBM Corp.).

\section{Results}

Study_population and baseline characteristics

Out of the 683 patients admitted to both medical centers, 81 lived outside Jerusalem and hence were excluded from the study. The remaining 602 patients comprised the study population (Figure 1). Of them 361 (60\%) were Ultra-Orthodox Jews; 166 (27.5\%) non-Ultra-Orthodox Jews and 75 (12.5\%) Arabs. Although Ultra-Orthodox Jews constitute only $22 \%$ of the total population and $36 \%$ of the Jewish 
population in Jerusalem, their admission rate among the total COVID-19 patients and among the Jewish COVID-19 patients was disproportionately high - (361/602) 60\% and (361/527) 68.5\% respectively. Arabs patients were younger than the Ultra-Orthodox Jews and the non-Ultra-Orthodox Jews ( $51 \pm 18$ year-old, $57 \pm 21$ and $59 \pm 19$, respectively, $p<0.01)$. Interestingly, more females were admitted among the Arabs than among Ultra-Orthodox and non-Ultra-Orthodox Jews (61.3\% vs. $44.0 \%$ and $44.6 \%$, respectively, $\mathrm{p}<0.05)$. Patients baseline characteristics and prior medical therapy are presented in Table 1. Arab patients suffered from significantly more co-morbidities such as dyslipidemia, hypertension, diabetes mellitus, smoking, prior atherosclerosis vascular disease, prior revascularization and heart failure than the two Jewish populations.

\section{Presenting signs and symptoms}

Patients presenting signs and symptoms at admission are listed in Table 2. Although the Arab patients had more co-morbidities, the main signs and symptoms at admission: fever, cough, dyspnea and fatigue, were more prominent in the Ultra-Orthodox and non-Ultra-Orthodox Jews patients as compare with the Arabs patients as presented in Figure 2.

\section{Clinical course of admission}

Length of admission was longer in the Ultra-Orthodox and the non-Ultra-Orthodox Jews patients as compared with the Arabs patients ( $10.70 \pm 11.18$ days vs. $9.21 \pm 8.68$ days vs. $6.41 \pm 11.2$ days, respectively, $p<0.01)$. During the course of admission, the rate of ACS, arrythmias, heart failure, VTE, CVA, revascularization and the use of mechanical support devices, cardiopulmonary resuscitation, acute respiratory distress syndromes, mechanical ventilation, acute kidney injury, the use of renal replacement therapy, co-infections were similar between groups. Nevertheless, hemodynamic shock, ischemic ECG changes and pathological chest $\mathrm{x}$-ray were all more frequent in the Ultra-Orthodox patients as compared with the other groups as presented in Table 3. Interestingly, mean troponin I levels were similar between Ultra-Orthodox, non-Ultra-Orthodox Jews and Arabs patients (438.88 \pm 2606.63 vs. $214.33 \pm 1201.08$ vs. 425.57 \pm 2343.17 , respectively, $p=0.2$ ), although d-dimer levels were higher among Ultra-Orthodox patients as compared with the non-Ultra-Orthodox Jews and Arabs patients $(1650.27 \pm 3785.47$ vs. $1077.97 \pm 1250.13$ vs. $927.03 \pm 1298.88$, respectively, $p<0.05$ ). Medical treatment with low molecular weight heparin or heparin was administrated in similar rate between Ultra-Orthodox, non-Ultra-Orthodox Jews and Arabs patients during admission ( $39.8 \%$ vs. $40.9 \%$ vs. $44.6 \%$, respectively, $p=0.75$ ).

\section{Major Adverse Cardiovascular Events and Mortality}

Fifty-four (9\%) patients died during hospitalization and none during the 30-day follow-up period. Sixty (10\%) patients experienced MACE. MACE rate was higher in Ultra-Orthodox patients as compared with non-Ultra-Orthodox Jews and Arabs patients ( $12.3 \%$ vs. $7.4 \%$ vs. $5.5 \%$, respectively, $p<0.05)$. Multivariable logistic regression model for MACE found that being a Ultra-Orthodox was independently associated with a significantly higher rate of MACE $[O R=1.96 ; 95 \% \mathrm{Cl}(1.03-3.71), p<0.05]$ as well as age and male gender [OR=1.04; $95 \% \mathrm{Cl}(1.02-1.07)$ and 2.34; $95 \% \mathrm{Cl}(1.25-4.37)$, respectively, $\mathrm{p}<0.01$ for both] as shown in 
Table 4. Mortality rate was higher among older patients and was increased exponentially in relate to age as shown in Figure 3. It was also higher if the patient had any cardiovascular risk factor (9.2\%) vs. none $(0.9 \%), p<0.01$. Moreover, it tended to be higher among Ultra-Orthodox Jews as compared with non-UltraOrthodox Jews and Arabs but did not reach statistical significance $(10.2 \%$ vs. $7.2 \%$ vs. $6.7 \%$, respectively, $p=0.4)$. Finally, there was no difference in mortality rate in relate to gender $(4.8 \%$ for female vs. $4.2 \%$ for male, $p=0.2$ ). Multivariable logistic regression model adjusted for age, any cardiovascular risk factor, gender and Ultra-Orthodox ethnicity, found that age was the only independent characteristic associated with increased mortality rate [OR=1.10; $95 \% \mathrm{Cl}(1.07-1.13), \mathrm{p}<0.001]$.

\section{Discussion}

Our study discovered four major findings regarding the different ethnical and cultural groups of confirmed COVID-19 patients admitted in Jerusalem: the Ultra-Orthodox Jews admission rate was, by far, the highest among all confirmed COVID-19 patients in Jerusalem, they had the worse clinical manifestations on admission (i.e. hemodynamic shock, ischemic ECG changes and pathological chest $x-$ ray) and being ultraorthodox Jew was independently associated with significantly higher rate of MACE events. Nevertheless, age was the only independent characteristic associated with increased mortality rate.

Although Ultra-Orthodox Jews constitute only $36 \%$ of Jewish population and roughly $22 \%$ of the total population in Jerusalem, the rates of admission among Jewish COVID-19 patients and total COVID-19 patients were $68.5 \%$ and $60 \%$, respectively. These findings are probably related to higher incidence and more severe disease among this population necessitating hospitalization and potentially to later referral to hospitalization. There may be several mechanisms underlying these phenomena. One is the fact that Ultra-Orthodox Jews live in large and dense families, many of them practice Torah studies and prayers in large densely populated groups. All these characteristics and behaviors may accelerate the spread of the disease $(15-18,24)$. Another potential mechanism contributing to the spread and severity of the disease may be related to late adoption of personal and social protection measures, and late identification and reaction to symptoms, due to lack of sufficient knowledge about the disease and rejection of information from governmental sources. The Ultra-Orthodox Jewish society is a close society that is characterized by low rate of exposure to TV $(26)$ lack of use of smartphones and computers $(26,27)$ affecting access to news and to health authorities' announcements. This society tends to follow religious leaders' authority rather than governmental or municipal authorities. It took several more weeks for the UltraOrthodox Jewish society to acknowledge and understand the severity of the pandemic, and for the government to create effective communications with the leadership and the public of the Ultraorthodox neighborhoods to explain and educate about the disease and prevention measures. Interestingly, similar trends of high rate and severity of morbidity were reported among other ultraorthodox neighborhoods in Israel and in New York City (28-30). The current observations of increased vulnerability to epidemics among ultraorthodox communities are in line with other infectious diseases outbreaks among them. During March 2018-May 2019, an outbreak of 4,115 measles cases occurred in Israel. Approximately one-half of the cases $(2,202)$ occurred in Jerusalem District, primarily in unvaccinated children in 
Orthodox Jewish communities (31). In February 2015, an outbreak of Shigella sonnei occurred in the Ultra-Orthodox Jewish community in Montréal while in December 2014, similar outbreak affecting two similar communities occurred in New York City $(32,33)$. Interestingly, although the Arabs patients suffered more from co-morbidities, the four major presenting symptoms (fever, cough, dyspnea and fatigue) and length of stay were more prominent among Jews patients. This might be explained by the fact that the Arabs patients were younger in almost a decade than the Jews patients.

Study limitations: Our study had several limitations: 1) Although we collected data from the two main and only medical centers in Jerusalem for COVID19 patients, we do not have data regarding patients from Jerusalem who were admitted to hospitals outside of Jerusalem, nor we have data from the community, regarding patients with confirmed COVID-19 infectious with mild disease, who stayed at home or other facilities. 2) The follow-up in the study was short with no long-term follow-up.

\section{Conclusion}

while older age was noted to be the most important risk factor for mortality in COVID-19 patients as was previously reported (34). Ultra-Orthodox Jews had the highest admission rates, more severe clinical presentation and higher complications rate as compared with either non-Ultra-Orthodox Jews and Arabs patients. Ethnic, social, cultural and predisposition may play a role in this phenomenon which may be relevant in areas worldwide which are inhabited by vulnerable populations for COVID 19 infection. Health authorities should pay special and early attention and quickly intervene in closed crowded and culturally isolated populations.

\section{Declarations}

\section{Competing interests}

All authors declare they have no competing interests for this article

\section{Funding}

None

\section{Authors' contributions}

Elad Asher- Pl; Tal Samuel- Data collection; Oren Yagel- Data collection; Arik Wolak - Drafting; Rivka Farkash-Statistics; Ronen Durst- Revision for important intellectual content; Eli Ben-Chetrit - Revision for important intellectual content; Yigal Helviz -Data collection; Ariella Tvito- Revision for important intellectual content; Ran Nir-Paz Offer Amir- Drafting and final approval; Michael Glikson- Drafting and final approval.

Acknowledgements 
Not applicable

Consent for publication

Not applicable

Availability of data and materials

All data are available with the corresponding author

\section{References}

1. Naming the coronavirus disease (COVID-19) and the virus that causes it". World Health Organization (WHO).

2. Novel Coronavirus-China". World Health Organization (WHO). Retrieved 9 April 2020.

3. Statement on the second meeting of the International Health Regulations (2005) Emergency Committee regarding the outbreak of novel coronavirus (2019-nCoV)". World Health Organization (WHO). 30 January 2020. Archived from the original on 31 January 2020. Retrieved 30 January 2020.

4. "WHO Director-General's opening remarks at the media briefing on COVID-19-11 March 2020". World Health Organization. 11 March 2020. Retrieved 11 March 2020.

5. Banerjee A, Pasea L, Harris S, et al. Estimating excess 1-year mortality associated with the COVID-19 pandemic according to underlying conditions and age: a population-based cohort study. Lancet 2020; 395: 1715-25.

6. Waitzberg R, Davidovitch N, Leibner G, et al. Israel's response to the COVID-19 pandemic: tailoring measures for vulnerable cultural minority populations. Int J Equity Health. 2020;19(1):71.

7. McCarty TR, Hathorn KE, Redd WD, et al. How Do Presenting Symptoms and Outcomes Differ by Race/Ethnicity Among Hospitalized Patients with COVID-19 Infection? Experience in Massachusetts [published online ahead of print, 2020 Aug 22]. Clin Infect Dis. 2020;ciaa1245.

8. Vahidy FS, Nicolas JC, Meeks JR, et al. Racial and ethnic disparities in SARS-CoV pandemic: analysis of a COVID-19 observational registry for a diverse US metropolitan population. BMJ Open. 2020;10(8):e039849.

9. Abuelgasim E, Saw LJ, Shirke M, et al. COVID-19: unique public health issues facing black, Asian and minority ethnic communities. Curr Probl Cardiol 2020;45:100621.

10. Israel confirms first coronavirus case as cruise ship returnee diagnosed". The Times of Israel. 21 February 2020. Archived from the original on 21 February 2020. Retrieved 21 February 2020.

11. OECD statistics. Available at: https://stats.oecd.org/.

12. Michal Korach, Dr. Maya Choshen The Jerusalem Institute for Policy Research. Publication no. 530 Jerusalem: Facts and Trends 2020. 
13. Bressler T, Dambra-Candelaria LM, Spatz DL. Informal Milk Sharing for the Hospitalized at-Risk Infant in the Ultra-Orthodox-Haredi Jewish Community in the United States. Breastfeed Med. 2020;15(5):335-340.

14. Schick, Marvin. "A Census of Jewish Day Schools in The United States"

15. Friedman M. The Haredi Ultra-Orthodox Society: Sources, Trends and Processes. Jerusalem: The Jerusalem Institute for Israel Studies; 1991.

16. Zicherman H. Black, Blue and White: A Journey into the Haredi Community in Israel. Tel Aviv, Israel: Yedioth Books; 2014.

17. Cahaner L, Yozgof-Orbach N, Sopher A. The Haredimin Israel: Space, Society, Community. Haifa, Israel: Chaikin Chair for Geostrategy, Haifa University; 2012.

18. Layosh B. Women of the Threshold: Orthodox Women in Front of a Modern Change. Tel Aviv, Israel: Resling Publishers; 2014.

19. Arabs Are Israel's New Yuppies. Haaretz. 13 June 2017.

20. Statistical Abstract of Israel, Central Bureau of Statistics, 2016, Table 5.4.

21. Daoud N, Soskolne V, Mindell JS, et al. Ethnic inequalities in health between Arabs and Jews in Israel: the relative contribution of individual-level factors and the living environment. Int J Public Health. 2018;63(3):313-323.

22. Israel Center for Disease Control (2011) The Health status in Israel, 2010. Ministry of Health, Jerusalem.

23. MJB special analysis of Central Bureau of Statistics data, 2000 and 2016, Table 8.71.

24. https://www.latimes.com/world-nation/story/2020-04-07/ultra-orthodox-jews-hit-disproportionatelyhard-in-israels-coronavirus-outbreak.

25. Szekely Y, Lichter Y, Taieb P, Banai A, Hochstadt A, Merdler I, Gal Oz A, Rothschild E, Baruch G, Peri Y, Arbel Y, Topilsky Y. Spectrum of Cardiac Manifestations in COVID-19: A Systematic Echocardiographic Study. Circulation. 2020 Jul 28;142(4):342-353.

26. Yamin D, Gavious A, Davidovitch N, et al. Role of intervention programs to increase influenza vaccination in Israel. Isr J Health Policy Res. 2014;3:13. Published 2014 Apr 25. doi:10.1186/20454015-3-13.

27. https://www.reuters.com/article/us-health-coronavirus-israel-ultraorthod/israels-ultra-orthodox-jewstake-to-internet-in-coronavirus-lockdown-idUSKCN225265?il=0

28. https://www.nytimes.com/2020/10/05/nyregion/orthodox-jewish-nyc-coronavirus.html

29. https://www.washingtonpost.com/religion/2020/10/08/orthodox-jewish-leaders-sue-block-new-yorkrestrictions-where-covid-19-cases-are-rising/

30. https://www.haaretz.com/us-news/.premium-n-y-c-to-reinstate-lockdown-restrictions-in-orthodoxjewish-covid-19-hotspots-1.9209041

31. Stein-Zamir C, Abramson N, Shoob H. Notes from the Field: Large Measles Outbreak in Orthodox Jewish Communities - Jerusalem District, Israel, 2018-2019. MMWR Morb Mortal Wkly Rep. 
2020;69(18):562-563. Published 2020 May 8. doi:10.15585/mmwr.mm6918a3.

32. Pilon PA, Camara B, Bekal S. Outbreak of Shigella sonnei in Montréal's ultra-Orthodox Jewish community, 2015. Can Commun Dis Rep. 2016;42(4):89-95. Published 2016 Apr 7. doi:10.14745/ccdr.v42i04a03.

33. New York City Department of Health and Mental Hygiene. 2014 Alert \#39: Outbreak of shigellosis in Borough Park and Williamsburg, December 17, 2014; [2 p.].

34. https://www.cdc.gov/coronavirus/2019-ncov/need-extra-precautions/older-adults.html Munster, V. J., Koopmans, M., van Doremalen, N., van Riel, D., \& de Wit, E. (2020). A novel coronavirus emerging in China-key questions for impact assessment. New England Journal of Medicine, 382(8), 692-694.

\section{Tables}

Table 1: Patients' baseline characteristics and prior medical therapy

\begin{tabular}{|lllll|}
\hline & $\begin{array}{l}\text { Ultra-Orthodox } \\
\text { Jews } \\
\text { 361 (60\%) }\end{array}$ & $\begin{array}{l}\text { Non-Ultra-Orthodox } \\
\text { Jews }\end{array}$ & $\begin{array}{l}\text { Arabs } \\
\mathbf{1 6 6}(\mathbf{2 7 . 5} \%)\end{array}$ & $\begin{array}{l}\text { p- } \\
\text { value } \\
(\mathbf{1 2 . 5} \%)\end{array}$ \\
\hline Age, mean (SD), y & $57( \pm 21)$ & $59( \pm 19)$ & $51( \pm 18)$ & $<0.01$ \\
\hline Female, $\%$ & $44.0 \%$ & $44.6 \%$ & $61.3 \%$ & $<0.05$ \\
\hline Dyslipidemia & $22.6 \%$ & $26.5 \%$ & $68.4 \%$ & $<0.01$ \\
\hline Hypertension & $38.4 \%$ & $45.4 \%$ & $71.1 \%$ & $<0.01$ \\
\hline Diabetes mellitus & $26.7 \%$ & $30.2 \%$ & $69.0 \%$ & $<0.01$ \\
\hline Smoking & $4.7 \%$ & $13.9 \%$ & $20.8 \%$ & $<0.01$ \\
\hline $\begin{array}{l}\text { Prior Atherosclerosis vascular } \\
\text { disease }\end{array}$ & $13.8 \%$ & $18.3 \%$ & $41.4 \%$ & $<0.01$ \\
\hline Prior Revascularization & $4.7 \%$ & $4.9 \%$ & $26.1 \%$ & $<0.01$ \\
\hline Heart Failure & $11.9 \%$ & $10.5 \%$ & $33.3 \%$ & $<0.01$ \\
\hline Aspirin & $14.8 \%$ & $25.2 \%$ & $46.9 \%$ & $<0.01$ \\
\hline Any anti-coagulation & $8 \%$ & $8 \%$ & $10 \%$ & 0.55 \\
\hline Beta Blockers & $16.1 \%$ & $22.1 \%$ & $45.2 \%$ & $<0.01$ \\
\hline ACE-I/ARBs & $20.2 \%$ & $30.2 \%$ & $40.7 \%$ & $<0.01$ \\
\hline Statins & $22.9 \%$ & $26.0 \%$ & $58.1 \%$ & $<0.01$ \\
\hline
\end{tabular}


Table 2: Patients presenting signs and symptoms at admission

\begin{tabular}{|c|c|c|c|c|c|}
\hline & $\begin{array}{l}\text { Ultra-Orthodox } \\
\text { Jews } \\
361(60 \%)\end{array}$ & $\begin{array}{l}\text { Non-Ultra-Orthodox } \\
\text { Jews } \\
166(27.5 \%)\end{array}$ & $\begin{array}{l}\text { Arabs } \\
75 \\
(12.5 \%)\end{array}$ & All & p-value \\
\hline & & & & 602 & \\
\hline Fever & $56.8 \%$ & $44.0 \%$ & $10.7 \%$ & $47.5 \%$ & $<0.0001$ \\
\hline Cough & $40.7 \%$ & $36.7 \%$ & $14.7 \%$ & $36.4 \%$ & 0.0001 \\
\hline Dyspnea & $31.0 \%$ & $21.7 \%$ & $18.7 \%$ & $26.9 \%$ & 0.021 \\
\hline Fatigue & $21.1 \%$ & $19.3 \%$ & $4.0 \%$ & $18.4 \%$ & 0.002 \\
\hline Chest Pain & $8.3 \%$ & $6.6 \%$ & $9.3 \%$ & $8.0 \%$ & 0.740 \\
\hline Myalgia & $6.4 \%$ & $9.0 \%$ & $5.3 \%$ & $7.0 \%$ & 0.449 \\
\hline Diarrhea & $8.3 \%$ & $6.0 \%$ & $2.7 \%$ & $7.0 \%$ & 0.186 \\
\hline Anosmia & $6.9 \%$ & $9.0 \%$ & $1.3 \%$ & $6.8 \%$ & 0.089 \\
\hline Anorexia & $8.3 \%$ & $6.0 \%$ & $0.0 \%$ & $6.6 \%$ & 0.029 \\
\hline Headache & $6.1 \%$ & $4.8 \%$ & $4.0 \%$ & $5.5 \%$ & 0.698 \\
\hline Chills & $5.5 \%$ & $6.0 \%$ & $1.3 \%$ & $5.1 \%$ & 0.271 \\
\hline Sore Throat & $3.6 \%$ & $4.8 \%$ & $0.0 \%$ & $3.5 \%$ & 0.166 \\
\hline Abdominal Pain & $2.5 \%$ & $2.4 \%$ & $2.7 \%$ & $2.5 \%$ & 0.993 \\
\hline Vomiting & $1.7 \%$ & $2.4 \%$ & $1.3 \%$ & $1.8 \%$ & 0.790 \\
\hline $\begin{array}{l}\text { Pleuritic Chest } \\
\text { Pain }\end{array}$ & $2.2 \%$ & $0.6 \%$ & $0.0 \%$ & $1.5 \%$ & 0.191 \\
\hline Palpitations & $1.4 \%$ & $1.8 \%$ & $0.0 \%$ & $1.3 \%$ & 0.520 \\
\hline Rhinorrhea & $0.8 \%$ & $3.0 \%$ & $0.0 \%$ & $1.3 \%$ & 0.071 \\
\hline Malaise & $0.3 \%$ & $1.2 \%$ & $0.0 \%$ & $0.5 \%$ & 0.301 \\
\hline Syncope & $0.6 \%$ & $0.0 \%$ & $0.0 \%$ & $0.3 \%$ & 0.512 \\
\hline Vertigo & $0.0 \%$ & $0.6 \%$ & $0.0 \%$ & $0.2 \%$ & 0.268 \\
\hline Hypothermia & $0.3 \%$ & $0.0 \%$ & $0.0 \%$ & $0.2 \%$ & 0.716 \\
\hline
\end{tabular}


Table 3: Hemodynamic Shock, Ischemic ECG changes and pathological chest X-ray during admission

\begin{tabular}{|c|c|c|c|c|}
\hline & $\begin{array}{l}\text { Ultra-Orthodox Jews } \\
361(60 \%)\end{array}$ & $\begin{array}{l}\text { Non-Ultra-Orthodox Jews } \\
166(27.5 \%)\end{array}$ & $\begin{array}{l}\text { Arabs } \\
75 \text { (12.5\%) }\end{array}$ & p-value \\
\hline $\begin{array}{l}\text { Shock during } \\
\text { admission }\end{array}$ & $10.1 \%$ & $5.6 \%$ & $2.7 \%$ & $<0.05$ \\
\hline Ischemic ECG Changes & $33.2 \%$ & $26.8 \%$ & $5.6 \%$ & $<0.01$ \\
\hline $\begin{array}{l}\text { Pathological chest X- } \\
\text { ray }\end{array}$ & $54.7 \%$ & $38.1 \%$ & $17.8 \%$ & $<0.01$ \\
\hline
\end{tabular}

Table 4: Multivariable logistic regression models for mortality and major adverse cardiac events

\begin{tabular}{lllllll} 
& \multicolumn{2}{l}{ Model $\mathbf{1}-$ Mortality } & \multicolumn{4}{l}{ Model 2 MACE } \\
& OR & $\mathbf{9 5 \%} \mathbf{C l}$ & p-value & OR & $\mathbf{9 5 \%}$ Cl & p-value \\
\hline Ultra-orthodox Jews & 1.46 & $0.76-2.82$ & 0.258 & 1.96 & $1.03-3.71$ & 0.039 \\
\hline Age & 1.10 & $1.07-1.13$ & $<0.001$ & 1.04 & $1.02-1.07$ & $<0.001$ \\
\hline Any cardiac risk factor & 1.71 & $0.60-4.87$ & 0.317 & 1.39 & $0.66-2.94$ & 0.39 \\
\hline Male gender & 1.17 & $0.62-2.24$ & 0.626 & 2.34 & $1.25-4.37$ & 0.008
\end{tabular}

Figures 


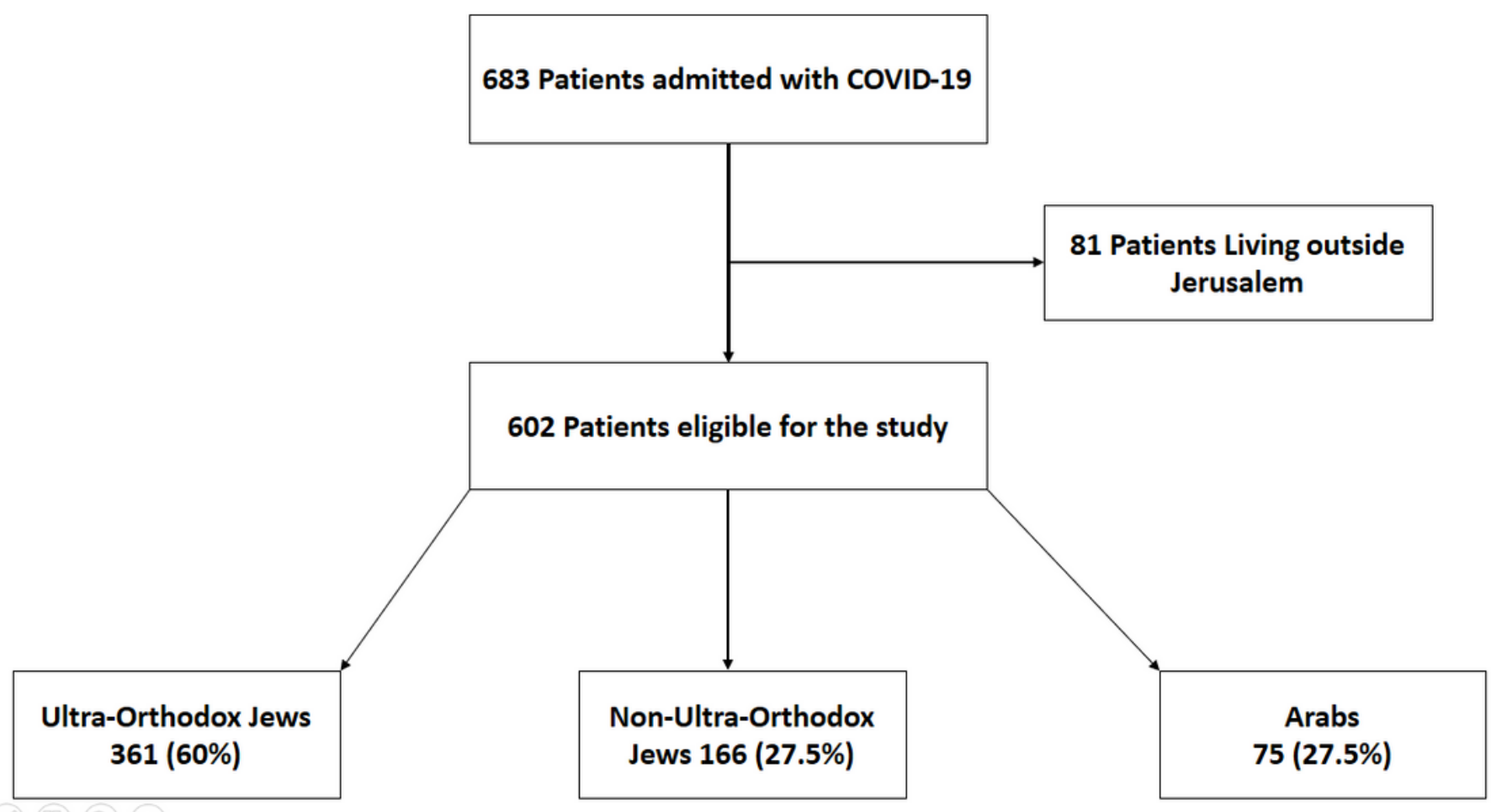

\section{Figure 1}

See image above for figure legend 


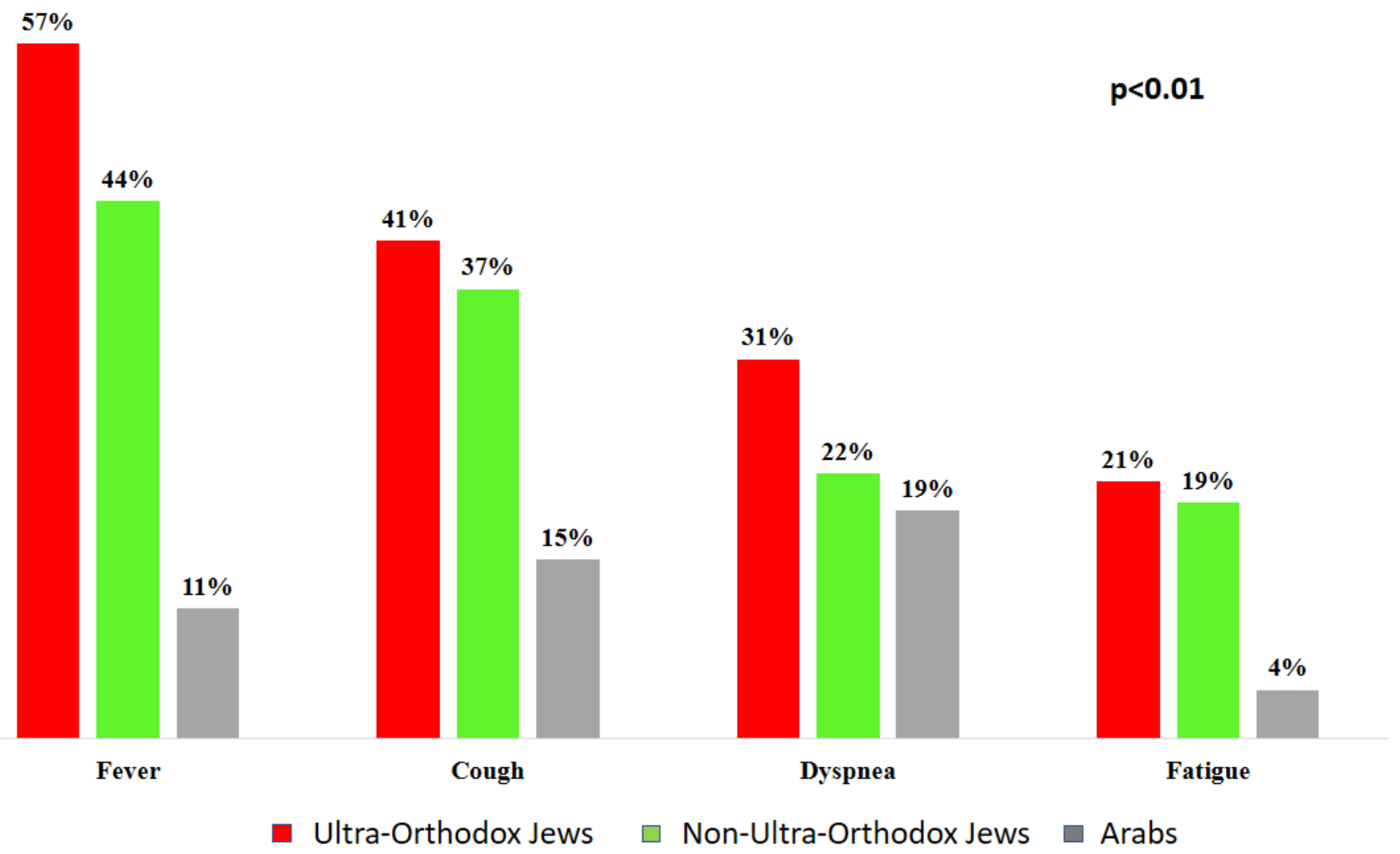

Figure 2

See image above for figure legend 
Figure 3: Mortality rate (\%) by age groups

p for trend $<0.001$

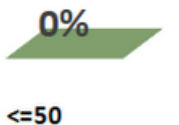

$<=50$

\section{$4.8 \%$}

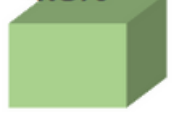

51-60

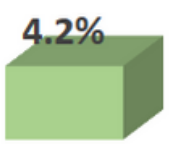

61-70

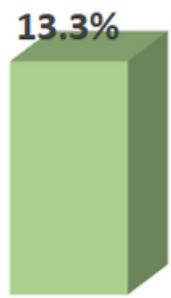

$71-80$
$45.8 \%$

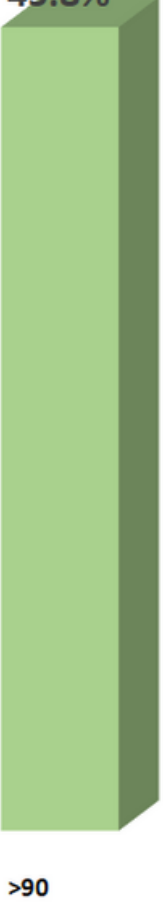

Figure 3

See image above for figure legend 